\title{
Impact of Price-Sensitive Demand and Premium Payment Scheme on Bullwhip Effect
}

\author{
Mona Verma, Shaheed Sukhdev College of Business Studies, University of Delhi, India \\ Reena Jain, Department of Operational Research, University of Delhi, India \\ Chandra K. Jaggi, Department of Operational Research, University of Delhi, India \\ (iD) https://orcid.org/0000-0001-6179-8376
}

\begin{abstract}
Bullwhip effect reduces the efficiency, responsiveness, and value of the supply chain. There are some indirect causes like lead time, the number of echelons, and some direct causes of bullwhip effect such as rationing or price variation. Due to capacity constraints, retailers are forced to experience rationing of their demands. Fear of rationing usually gives rise to manipulable demand and hence increases the bullwhip effect. Moreover, if the retailer's demand is price sensitive, it will cause price variation. The offerings of premium payment by retailers due to unfulfilled demand lure the supplier to extend his existing capacity and to allocate them more supply. In this paper, an attempt has been made to mitigate the impact of the bullwhip effect using a premium payment scheme. A technique has been coined that will help in reducing the bullwhip effect. The increased value of the supply chain on using a premium payment scheme is proof of the reduction of the bullwhip effect. Results are validated through numerical analysis.
\end{abstract}

\section{KEYWORDS}

Bullwhip Effect, Capacity Constraint, Premium Payment Scheme, Price Variation, Price-Sensitive Demand, Rationing

\section{INTRODUCTION}

A supply chain system includes all the communications among suppliers, manufacturers, retailers and customers. The amalgamation of information in the form of demand and supply at manufacturing sites in the context of the supply chain has become more practical and has attracted the attention of both industry practitioners and academic researchers. This information needs to be propagated correctly to an upstream member from downstream members. Distortion in this information or amplification of demand on traversing the information in the form of orders from lower echelon to higher echelon is termed as the "bullwhip effect". Lee et al. (1997a) discussed the direct causes of bullwhip effect under four categories viz. demand signal processing, order batching, price variation and rationing. However, some indirect causes also exist such as lead time, the number of echelons in the supply chain (Agrawal, et. al, 2009, Chatfield et al. 2004).

Whenever there is a capacity constraint, the rationing of resources arises, which builds a bullwhip effect. To lure the supplier, the retailers offer premium payment for the unfulfilled demand so that 
the supplier can extend his existing capacity and allocate them more supply. Further, in practice, retailers may experience price-sensitive demand which will also amplify bullwhip effect. In literature, price-sensitive demand has been discussed either in isolation or with other factors such as trade credit, inflation, deterioration, multiple items and many more. All the above mentioned situations have been formulated to find the optimal price for the retailer, which jointly optimizes the supply chain profit. However, to the best of our knowledge, the impact on bullwhip effect under the pricesensitive demand in a monopolistic environment with capacity constraint and premium payment has not been explored so far.

This research gap has motivated us to frame the model under the aforementioned state. When the capacity constraint is active, two scenarios have been assumed i.e. either the retailer's selling price or the retailer's demand will be considered as an independent decision variable. In the first case selling price of retailers is taken as a decision variable. Its optimal value calculated from the model is substituted in demand function to get the value of the retailer's demand. In the second case retailer's demand is taken as a decision variable. The optimal value of demand is substituted in demand function to get the value of selling price. Further, it has been discussed whether it is beneficial for the supplier to extend his existing capacity or not while getting premium payment from the retailers. To explore the situation completely four mathematical models comprising of linear programming and non-linear programming problems are framed. These mathematical models are solved numerically using software Lingo. A sensitivity analysis has been done to validate the results.

The paper is divided into eight sections. The first section is an introduction followed by a literature review. The basic assumptions and notations are explained in section 3 . The problem is described and formulated in section 4 . To strengthen the findings of the preceding section, numerical analysis is done in section 5, followed by a sensitivity analysis to study the impact of different parameters in section 6 . In section 7 managerial implications are provided. The results are concluded in section 8 .

\section{LITERATURE REVIEW}

In this section relevant literature related to bullwhip effect, price-sensitive demand, rationing and premium payment scheme is discussed one by one.

\section{Bullwhip Effect}

Forrester (1961) introduced the term bullwhip effect by studying the variability or amplification in demand as the order's information moves from lower echelon to higher echelon. Approximately for four decades, the term remains unexplored. Afterward, Lee et al. (1997a) extended the work of Forrester (1961) and addressed four direct causes of the bullwhip effect. They suggested some remedies also to mitigate it. Cachon and Lariviere (1999a, b) explored the impact of rationing on the bullwhip effect. They proved that some rationing mechanisms favor inflation and while some other favors deflation of demand. All the mechanism follows manipulating the demand. Kelle et al. (1999) studied the impact of order batching on the bullwhip effect. Geary et al. (2006) explained ten published reasons for the bullwhip effect and discussed the impact of them on the health of the supply chain. Chopra and Meindl (2006) addressed the impact of bullwhip effect on measures of performance of the supply chain. Hohmann and Zelewski (2011) explored the impact of using vendor managed inventory on the bullwhip effect. De (2013) analyzed the criticality of the bullwhip effect and proposed a multicriteria based approach for evaluating the performance of the whole supply chain. In the same year, the idea was used by Akkermans and Vos (2013) to unfold the causes of the bullwhip effect in the telecommunication industry. The field of bullwhip effect is quite vast. In literature, it is explored for its causes and remedies. Many researchers devised new techniques to reduce the bullwhip effect. Almost all the available literature about the bullwhip effect was summarized by Wang and Disney (2016) explored till 2016. Recently Wu et al. (2021) done an empirical study to explain that demand 
variability propagates through supply chain in upward direction and this variability is influenced by customer-retailer relationship.

\section{Price Sensitive Demand}

The price of a commodity is guided by the law of demand and supply. Fixing up of selling price is very vital as well as a crucial decision for any retailer. The situation becomes more critical when demand is sensitive to selling price. Many researchers studied different forms and combinations of pricesensitive demand. The price-sensitive nature of the demand was explored by Abad (2001), Polatoglu and Sahin (2000), Abad and Jaggi (2003), Ray et al. (2005), You and Hsieh(2007), Chen et al. (2010), Kim et al. (2011) and Chao et al. (2016) under various other practical settings like deterioration, partial backordering, credit period, lead time considerations, etc. Some of the researchers explored the price depending on more than one factor, for example, Alfares and Ghaithan (2016) developed an inventory model with a selling price-sensitive demand rate, time-varying holding cost, based on quantity discounts. The demand depending upon both the price and stock was explored by Mo et al. (2009). Recently, the demand depending upon the price, stock and time were studied by Chen et al. (2019). Liu et al. (2019) explored the customer's balking behavior in presence of price-sensitive demand. The impact of the fluctuating price on the bullwhip effect is empirically verified by Trapero and Pedregal (2016). However, some other researchers investigated this impact analytically too. Lee et al. (1997b), Hamister and Suresh (2008) and Sodhi et al. (2014) illustrated that the variation in prices will amplify the bullwhip effect, which can be minimized by stabilizing price. To alleviate the impact of price fluctuation on the bullwhip effect, Lee et al. (1997b) proposed some methods to regulate price, such as everyday low price (EDLP). However, this strategy has recently been dubious for its benefit (Wang and Disney, 2016). Some authors like Özelkan and Lim (2009) derived the conditions for reverse bullwhip effect under random price-sensitive demand. Almost all different types of demand functions have been considered by researchers till now. For instance, linear demand function (Kim et al., 2011), Quadratic demand function (Kumar et al., 2014) and selling price raise to the negative power of price elasticity as demand function (Abad and Jaggi, 2003) and many more. Recently, Tai et al (2019) claimed that a positive correlation between price and demand increases bullwhip effect whereas the negative correlation between price and demand can be used as a tool to fight against bullwhip effect.

\section{Rationing and Shortage Gaming}

In the field of allocation or rationing, many researchers contributed different allocation policies under a different scenario. Kaplan (1969) developed an algorithm that calculates optimum reserve levels, i.e., stock levels at which lower priority demand should be backlogged. Nahmias and Demmy (1981) extended the concept of Kaplan by defining a new control policy. Cachon and Lariviere (1999a) explored three allocation techniques depending upon the priority given based on the demand of retailers. They consider a multiple-period capacity allocation problem using a turn-and-earn allocation scheme. Approximately at the same time in their another article (Cachon and Lariviere, (1999b) they claimed that truth inducing mechanism for rationing policies is not as profitable as a manipulable mechanism. Jaggi et al. (2010) extended the concept of Cachon and Lariviere (1999b) and introduced the idea of reallocation for dual benefit of the supply chain. On one hand, it reduced the cost of inventory at the supplier's end by reallocating the items left with the supplier and on other hand, it helped in increasing the profit of the supply chain by providing better allocation to the retailers, who were dealing with shortages to some extent. The same idea was further extended by Jaggi et al. (2018) by the introduction of a new allocation mechanism, IPA (Iterative Proportional Allocation). This allocation mechanism was proved best in mitigating the bullwhip effect in the case of rationing. Mallik and Harker (2004) formulized the capacity allocation model in the semiconductor industry where the demand as well as the supply was random. Geng and Mallik (2007) explored the idea of allocation and inventory competition in a multi-channel distribution system. 


\section{Premium Payment Scheme}

The premium payment scheme has not been explored much by the researchers till now hence enough literature of interest is not available. However, Yang and Yang (2007) proved in their paper that a premium payment scheme can lure the supplier to extend his existing capacity.

In the present study, an attempt has been made to develop the mathematical models for two echelon supply chain consisting of single monopolistic supplier and multiple retailers. The supplier is dealing with capacity constraint situation while retailers are facing the issue of price-sensitive demand. The concept of premium payment is introduced to increase the capacity of the supplier. To the best of our knowledge, the literature regarding joint optimization of price-sensitive demand and rationing has not been discussed anywhere. The premium payment scheme along with the aforementioned factors is also not explored. The assumptions and notations used for the development of models are explained in the following section.

\section{ASSUMPTIONS AND NOTATIONS}

The formulation of models has been done under the following assumptions:

\section{Assumptions}

- The supplier has limited capacity and has a monopoly over the market.

- The supplier has adopted Iterative Proportional Allocation (IPA) (Jaggi et al., 2018) in the case of rationing.

- Retailers are also enjoying a monopoly in their vicinity because of geographical location.

- Demand at the retailer's end is very large and price-sensitive.

- Shortages are not allowed due to price-sensitive demand.

- Retailers are ready to pay the premium payment for getting a better share of supply. The numbers of units for which retailers are paying premium are called premium units.

- The supplier is liable to pay penalty for non-fulfillment of demand for premium units. The amount of penalty paid per unit would be greater than the amount of premium received per unit.

- The supplier can extend his capacity by incurring some extra unit cost up to some extent and the decision of accepting premium payment lies with the supplier.

- The planning horizon is taken as one cycle.

\section{Notations}

Following notations are used for mathematical modeling:

\section{MODEL DESCRIPTION AND FORMULATION}

In present study, a two echelon supply chain with $N$ retailers and one supplier is considered. The $N$ retailers are placing their demand to the supplier at the beginning of the cycle. They (retailers) are dealing with high price-sensitive demand with demand function $D_{i}\left(p_{i}\right)=a_{i}-b_{i} p_{i}$. Though the supplier is enjoying monopoly with limited capacity, yet he can extend his capacity up to some percentage on incurring an extra unit cost. In this scenario, there would not be any shortages because whatever supplier supplies, retailers ' selling prices would get adjusted according to that quantity due to price-sensitive demand. Now, since the demand at the retailer's end is price sensitive therefore, the price can be used to calculate the demand and demand can be used to calculate the price. Hence, a major issue with the aforementioned situation is, to identify the independent decision variable, out of the retailer's selling price and retailer's demand. Such type of approach is used in the paper to 
Table 1. Notations

\begin{tabular}{|c|c|c|}
\hline$N$ & : & Number of retailers. \\
\hline$D_{i}$ & : & Demand of $i^{\text {th }}$ retailer. \\
\hline$D_{i}\left(p_{i}\right)$ & : & $\begin{array}{l}\text { Demand function of } a n i^{\text {th }} \text { retailer is a function of selling price linearly decreasing with } \\
p_{i}, D_{i}\left(p_{i}\right)=a_{i}-b_{i} p_{i} \text {. Where } a_{i} \text { is constant demand rate coefficient and } b i \text { is price- } \\
\text { sensitive demand rate coefficient, } a_{i}, b_{i}>0 \text {. }\end{array}$ \\
\hline$P R_{i}$ & : & $\begin{array}{l}\text { The number of units for which premium amount is paid by the } i^{\text {th }} \text { retailer referred as premium } \\
\text { units. }\end{array}$ \\
\hline$K$ & : & Existing Capacity of the supplier. \\
\hline$W$ & : & Extended capacity of supplier. \\
\hline$h_{r i}$ & : & Inventory carrying cost per unit per cycle for an $i^{\text {th }}$ retailer. \\
\hline$h_{S}$ & : & Inventory carrying cost per unit per cycle for Supplier \\
\hline$\pi_{r i}$ & : & Profit of the $i^{\text {th }}$ retailer. \\
\hline$\pi_{S}$ & : & Profit of the supplier. \\
\hline$\pi$ & : & Joint profit of supplier and all retailers, i.e. supply chain profit. \\
\hline$C_{1} \in(0,+\infty)$ & : & The regular payment the retailer would make to the supplier for a unit item. \\
\hline$C_{2} \in(0,+\infty)$ & : & Supplier's unit production cost in regular production. \\
\hline$C_{3} \epsilon(0,+\infty)$ & : & Supplier's unit production cost in case of extending capacity. $C_{3}>C_{2}$. \\
\hline$\alpha \in(0,1)$ & : & The fraction of $C_{l}$ paid by the retailer to the supplier as a premium amount per unit. \\
\hline$\beta \in(0,1)$ & : & $\begin{array}{l}\text { The fraction of } C_{l} \text { paid by the supplier to the retailer as a penalty for non fulfillment of premium } \\
\text { units, where } \beta>\alpha \text {. }\end{array}$ \\
\hline
\end{tabular}

study the impact of price variation and rationing on the bullwhip effect in isolation. The models are developed under the situation of price variation and rationing due to limited capacity constraint. Both are direct and major causes of the bullwhip effect. When the price is taken as an independent decision variable, demand is calculated by substituting the optimal price into the demand function. It avoids rationing. Contrary to this, when demand is taken as an independent decision variable, routine capacity is allocated according to the Iterative proportional Algorithm (IPA) and then the optimal number of premium units (if required) to be allocated is calculated. This total demand is used in demand function to calculate the selling price. Through this approach, an attempt has been made to minimize the bullwhip effect. Furthermore, the present approach helps to make the decision about extending the existing capacity and the quantity by which it should be extended. Each case is discussed under two subcases that whether to extend the existing capacity or not.

The motive behind the idea is to capture maximum sales with optimum use of the supplier's set up. Moreover, substantial attention is given to the bullwhip effect so that rationing and price variation, 
the well-known factors responsible for the bullwhip effect could not amplify it. In the present paper, an attempt has been made to develop mathematical models to calculate the selling price of retailers and the number of units to be produced on extended capacity in case of price-sensitive demand and limited supply. Here, IPA has been used as an allocation policy, since it curbs the bullwhip effect to the maximum extent. To explain the problem clearly, it is divided into two cases which are further divided into two subcases each. The proposed model has been presented in Figure 1.

Figure 1. Model Framework of the problem under consideration

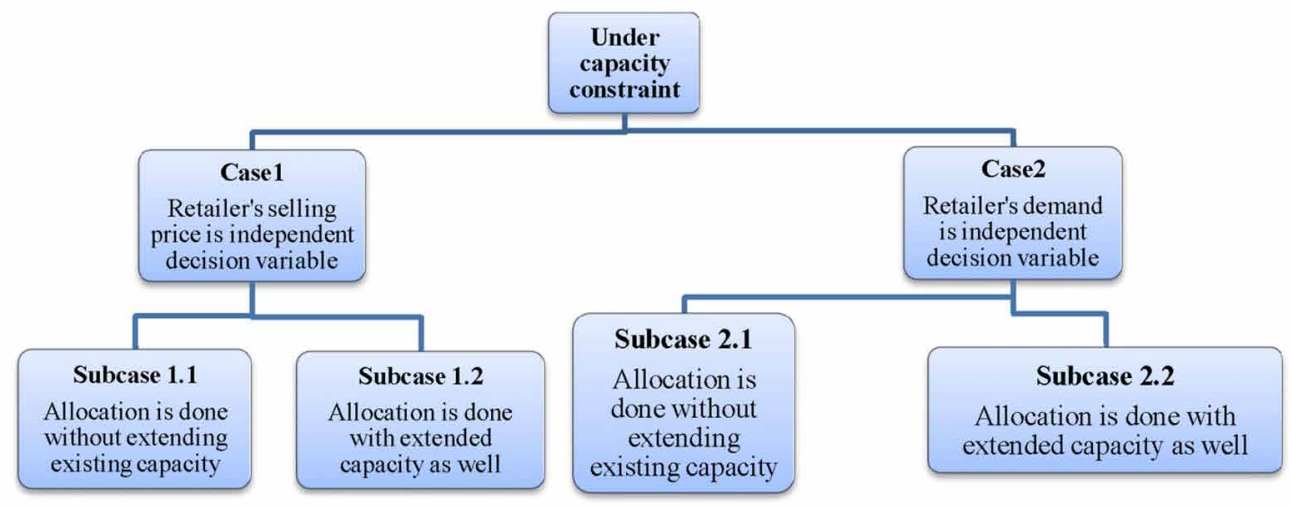

Each case and subcase stated in Figure 1 has been explained and mathematical models have been framed to get the optimal results under each situation.

Case 1: Retailer's Selling price is an independent decision variable

In this case, it is assumed that the selling price of retailers is an independent decision variable and the retailer's demand depends upon selling price. So under two stated subcases, the model is formulated to get the optimal selling price and hence demand.

Subcase 1.1: Allocation is done without extending the existing capacity

When the retailer's selling price is independent decision variable and allocation is done through existing capacity only, two individual mathematical problems i.e. one for $N$ retailers and one for the supplier are framed. These two problems are combined to optimize jointly and results are obtained. As the allocation is done through routine capacity only, premium payment would not come into the scenario. Firstly the joint optimization model is solved to calculate the retailer's optimal selling price. Then this selling price is used to calculate the demand for which allocations have been done. Since during the formulation of a joint optimization problem, the capacity of the supplier is taken as constraint, thus, total demand would not exceed the capacity of the supplier. The Optimization problem of retailer and supplier can be expressed as:

Retailer's Problem: 


$$
\operatorname{Max} \sum_{i=1}^{N} \pi_{r i}(p i)
$$

$=$ Total revenue - Totalcost price - Totalinventory carryingcost

$\operatorname{Max} \sum_{i=1}^{N} \pi_{r i}(p i)=\sum_{i=1}^{N}\left(p_{i}-C_{1}\right) D_{i}\left(p_{i}\right)-\frac{1}{2} \sum_{i=1}^{n} D_{i}\left(p_{i}\right)\left(h_{r i}\right)$

Subject to

$p_{i} \geq C_{1}+\frac{1}{2} h_{r i} \forall i=1 \ldots N$

$$
\sum_{i=1}^{N} D_{i}\left(p_{i}\right) \leq K
$$

$D_{i}\left(p_{i}\right) \geq 0 \forall i=1 \ldots N$

Supplier's Problem:

$\operatorname{Max}_{S}\left(p_{1}, p_{2}, \ldots \ldots p_{N}\right)=$ Revenue - Totalcost of regular production - inventory carryingcost

$$
\operatorname{Max}_{S}\left(p_{1}, p_{2}, \ldots \ldots p_{N}\right)=\left(C_{1}-C_{2}-\frac{1}{2} h_{S}\right) \sum_{i=1}^{N} D_{i}\left(p_{i}\right)
$$

Retailers and supplier are optimizing their profit function on common decision variables. Hence their profit function can jointly be optimized.

The joint optimization problem can be written as:

$$
\operatorname{Max} \pi\left(p_{1}, p_{2}, \ldots \ldots p_{N}\right)=\sum_{i=1}^{N} \pi_{r i}(p i)+\pi_{S}=\sum_{i=1}^{N} D_{i}\left(p_{i}\right)\left(p_{i}-C_{2}-\frac{1}{2}\left(h_{S}+h_{r i}\right)\right)
$$

On substituting $D_{i}\left(p_{i}\right)=a_{i}-b_{i} p_{i}$

$$
\operatorname{Max} \pi\left(p_{1}, p_{2}, \ldots \ldots p_{N}\right)=\sum_{i=1}^{N}\left(\left(a_{i}-b_{i} p_{i}\right)\left(p_{i}-C_{2}-\frac{1}{2}\left(h_{S}+h_{r i}\right)\right)\right)
$$




\section{Subject to}

$p_{i} \geq C_{1}+\frac{1}{2} h_{r i} \forall i=1 \ldots N$

$$
\sum_{i=1}^{N} a_{i}-b_{i} p_{i} \leq K
$$

$$
a_{i}-b_{i} p_{i} \geq 0 \forall i=1 \ldots N
$$

The joint profit function is expressed by equation (7) subject to the constraints (8)-(10). It is a quadratic programming problem in $N$ variables and can be solved using Lingo software. The $N$ optimal values of $p_{i}$ would be used to get $N$ allocations and joint profit can be calculated. The concavity of the stated model can be proved by proving the necessary and sufficient condition of the following theorem.

Theorem 1: In case of the multivariable non-linear objective function subject to linear constraints, if the Hessian matrix of the objective function is negative definite (semidefinite) then function possesses local (global) maxima of the objective function at a stationary point. (Osborne, 2007).

Proof: For $N$ variables, the Hessian matrix of the model represented by equation (7)-(10) can be expressed by $H$.

$$
H=\left(\begin{array}{ccccc}
-b_{1} & 0 & 0 & - & 0 \\
0 & -b_{2} & 0 & - & 0 \\
0 & 0 & -b_{3} & - & 0 \\
- & - & - & - & - \\
0 & 0 & 0 & - & -b_{N}
\end{array}\right)
$$

All Eigenvalues of $H$ would be $\left(-b_{i}\right)$, as $b_{i}>0, \forall i=1 \ldots N$. Hence, all Eigenvalues would be negative.

Therefore, joint profit function $\pi\left(p_{1}, p_{2}, \ldots \ldots p_{N}\right)$ represented by equation (7) would be negative definite. Hence subcase 1.1 would possess local maxima.

Subcase 1.2: Allocation is done with extended capacity as well.

In this subcase, the supplier is ready to accept premium payment and extend his existing capacity. Now, the allocation would be done from routine as well as extended capacity. In this situation along with selling prices of retailers, the premium units of each retailer will also be the decision variable. Hence, the number of decision variables would be $2 N$, i.e. $\left(p_{1}, p_{2}, \ldots, p_{N}\right.$ and $\left.P R_{l}, P R_{2}, \ldots, P R_{N}\right)$. The optimization problem of retailers and supplier can be expressed as: 
Retailer's Problem:

$\operatorname{Max} \sum_{i=1}^{N} \pi_{r i}\left(p_{i}, P R_{i}\right)$

$=$ Total revenue - Total cost price - Total inventory carryingcost

-Total premium payment paid + Total Penalty recieved

$\operatorname{Max} \sum_{i=1}^{N} \pi_{r i}\left(p_{i}, P R_{i}\right)$

$=\sum_{i=1}^{N}\left(p_{i}-C_{1}\right) D_{i}\left(p_{i}\right)-\frac{1}{2} \sum_{i=1}^{n} D_{i}\left(p_{i}\right) h_{r i}-\alpha C_{1} \sum_{i=1}^{N} P R_{i}$

$+\beta C_{1}\left(\sum_{i=1}^{N}\left(P R_{i}\right)-W\right)$

Subject to

$p_{i} \geq C_{1}+\frac{1}{2} h_{r i}+\alpha C_{1} \frac{P R_{i}}{D_{i}\left(p_{i}\right)} \quad \forall i=1 \ldots N$

$\sum_{i=1}^{N} D_{i}\left(p_{i}\right) \leq K+\mathrm{W}$

$W=\sum_{i=1}^{N} P R_{i}$

$D_{i}\left(p_{i}\right) \geq 0, P R_{i} \geq 0 \forall i=1 \ldots N$

$W, P R_{i}$ are integers $\forall i=1 \ldots N$

Supplier's Problem:

$\operatorname{Max}_{S}\left(p_{1}, p_{2}, \ldots \ldots p_{N}, P R_{1}, P R_{2}, \ldots, P R_{N}\right)$ 
$=$ Revenue - total cost of regular production - inventory carrying cost -

total cost of extended capacity + total premium payment received -

total Penalty paid

$\operatorname{Max}_{S}\left(p_{1}, p_{2}, \ldots \ldots p_{N}, P R_{1}, P R_{2}, \ldots, P R_{N}\right)$

$=\left(C_{1}-C_{2}-\frac{1}{2} h_{S}\right) \sum_{i=1}^{N} D_{i}\left(p_{i}\right)-\left(C_{3}-C_{2}\right) W+\alpha C_{1} \sum_{i=1}^{N} P R_{i}-\beta C_{1}\left(\sum_{i=1}^{N}\left(P R_{i}\right)-W\right)$

Similar to subcase 1.1, here also retailers and suppliers are optimizing their profit functions on common $2 N$ variables. Hence their problem can be jointly optimized.

Joint Problem:

$$
\begin{aligned}
& \operatorname{Max} \pi\left(p_{1}, p_{2}, \ldots \ldots p_{N}, P R_{1}, P R_{2}, \ldots, P R_{N}\right)(17) \\
& =\sum_{i=1}^{N} \pi_{r i}\left(p_{i} \cdot P R_{i}\right)+\pi_{S}\left(p_{1}, p_{2}, \ldots \ldots p_{N}, P R_{1}, P R_{2}, \ldots, P R_{N}\right)= \\
& \sum_{i=1}^{N}\left(D_{i}\left(p_{i}\right)\left(p_{i}-C_{2}-\frac{1}{2}\left(h_{S}+h_{r i}\right)\right)\right)-\left(C_{3}-C_{2}\right) \sum_{i=1}^{N} P R_{i}
\end{aligned}
$$

On substituting $D_{i}\left(p_{i}\right)=a_{i}-b_{i} p_{i}$

$$
\begin{aligned}
& \operatorname{Max} \pi\left(p_{1}, p_{2}, \ldots \ldots p_{N}, P R_{1}, P R_{2}, \ldots, P R_{N}\right) \\
& =\sum_{i=1}^{N}\left(\left(a_{i}-b_{i} p_{i}\right)\left(p_{i}-C_{2}-\frac{1}{2}\left(h_{S}+h_{r i}\right)\right)\right)-\left(C_{3}-C_{2}\right) \sum_{i=1}^{N} P R_{i}
\end{aligned}
$$

Subject to

$$
p_{i} \geq C_{1}+\frac{1}{2} h_{r i}+\alpha C_{1} \frac{P R_{i}}{a_{i}-b_{i} p_{i}} \quad \forall i=1 \ldots N
$$

$$
\sum_{i=1}^{N}\left(a_{i}-b_{i} p_{i}\right) \leq K+W
$$

$$
W=\sum_{i=1}^{N} P R_{i}
$$




$$
\begin{aligned}
& a_{i}-b_{i} p_{i} \geq 0, P R_{i} \geq 0 \forall i=1 \ldots N \\
& W, P R_{i} \text { areintegers } \forall i=1 \ldots N
\end{aligned}
$$

Figure 2. Joint supply chain profit w.r.t. selling price of 2 retailers

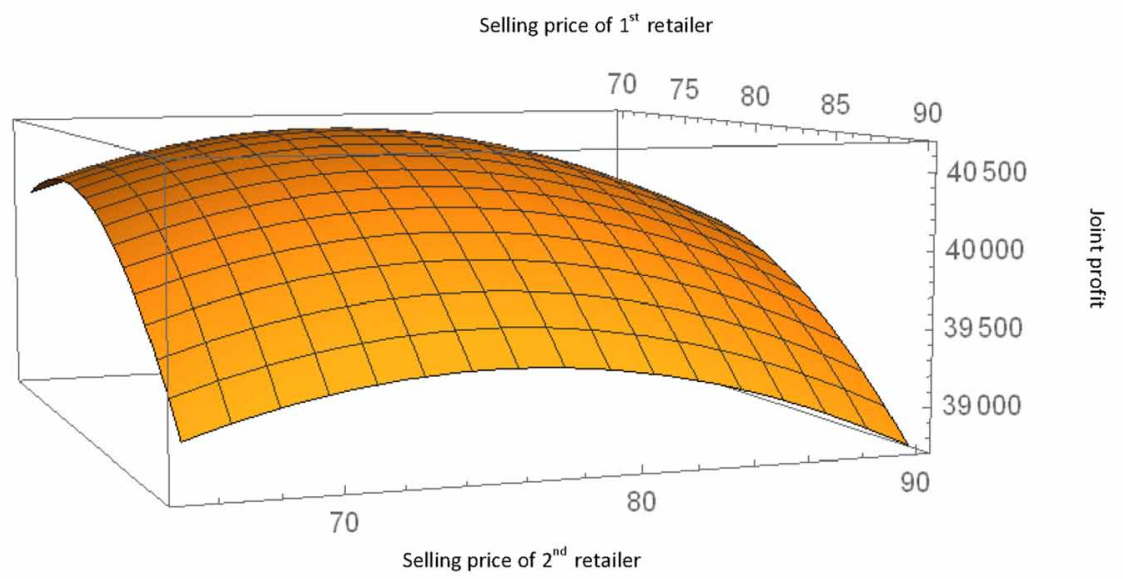

The problem expressed by equation number (18)-(22) is a non-linear programming problem in $2 N$ decision variables, which can be solved using Lingo software. As decision variables are large in number, its concavity has been proved graphically. Moreover, graphs between different combinations of $p_{i}$ and $P R_{i}$ have been studied and all are found concave. Due to simplicity and space constraint, only one graph is shown here. This graph is plotted using the software "Mathematica". In each combination, it is showing a concave disc, which suffices to prove its concavity (Figure 2).

Case 2: Retailer's Demand is an independent decision variable

In this case, the retailer's demand would be treated as decision variable and selling price would be calculated according to allocation under both the subcases, i.e. without extended capacity and with extended capacity.

\section{Subcase 2.1 Allocation is done without extending the existing capacity}

Here, firstly the existing capacity is allocated according to the rationing mechanism (IPA, Jaggi et al., 2018) and then the retailer's selling price is calculated. Since the retailer's demand is an independent decision variable and their selling price will depend on allocated demand, the model can be solved trivially. The retailer's optimization problem can be expressed as

Retailer's Problem: 
$\operatorname{Max} \sum_{i=1}^{N} \pi_{r i}\left(p_{i}\right)=$ Totalrevenue - Totalcost price - Total inventorycarryingcost

$\operatorname{Max} \sum_{i=1}^{N} \pi_{r i}\left(p_{i}\right)=\sum_{i=1}^{N}\left(p_{i}-C_{1}\right) D_{i}\left(p_{i}\right)-\frac{1}{2} \sum_{i=1}^{n} D_{i}\left(p_{i}\right) h_{r i}$

Subject to

$p_{i} \geq C_{1}+\frac{1}{2} h_{r i} \forall i=1 \ldots N$

$D_{i}\left(p_{i}\right)=a_{i}-b_{i} p_{i} \geq 0 \forall i=1 \ldots N$

The supplier is allocating demand according to the pre-announced allocation mechanism, so supplier's profit would be deterministic.

\section{Supplier's Problem:}

Max $\pi_{S}=$ Revenue - Totalcost of regular production - Totalinventorycarryingcost

$\operatorname{Max} \pi_{S}=\left(C_{1}-C_{2}-\frac{1}{2} h_{S}\right) \sum_{i=1}^{N} D_{i}$

Where $D_{i}$ is the demand of $i^{\text {th }}$ retailer known by allocation mechanism. In this case, only retailer's problem would be solved to get the optimal price using the demand function. The same selling prices are used to maximize supplier's profit.

The problem represented by equation number (23)-(25) is a linear programming problem. Moreover, equation (25) is making it bounded, so optimality is ensured. Hence out of all feasible points, the optimum point can be selected.

\section{Subcase 2.2: Allocation is done with extended capacity as well.}

In this situation, firstly existing capacity is allocated according to the rationing mechanism (IPA, Jaggi et al., 2018) and an $N$ variable mathematical model is framed for retailers to get the optimum number of premium units for each retailer. Similarly, a mathematical model for the supplier is framed to get the optimum value of extended capacity. These two models are jointly optimized to get the optimum value of premium units namely $P R_{1} P R_{2}, \ldots, P R_{N}$. Selling price would be evaluated using the demand function, where total allocation (allocation by rationing + premium units) would be treated as demand.

Here along with the conditions of subcase 2.1 , the feasibility of premium payment and extended capacity is also analyzed.

Retailer's Problem: 
$\operatorname{Max} \sum_{i=1}^{N} \pi_{r i}\left(P R_{i}\right)$

$=$ Total revenue - Total cost price - Total inventory carrying cost

-Total premium payment paid + Total Penalty recieved

$\operatorname{Max} \sum_{i=1}^{N} \pi_{r i}\left(P R_{i}\right)$

$=\sum_{i=1}^{N}\left(p_{i}-C_{1}\right) D_{i}\left(p_{i}\right)-\frac{1}{2} \sum_{i=1}^{n} D_{i}\left(p_{i}\right) h_{r i}-\alpha C_{1} \sum_{i=1}^{N} P R_{i}+\beta C_{1}\left(\sum_{i=1}^{N}\left(P R_{i}\right)-W\right)$

Subject to

$p_{i} \geq C_{1}+\frac{1}{2} h_{r i}+\alpha C_{1} \frac{P R_{i}}{D_{i}\left(p_{i}\right)} \quad \forall i=1 \ldots N$

$\sum_{i=1}^{N} D_{i}\left(p_{i}\right) \leq K+W$

$W=\sum_{i=1}^{N} P R_{i}$

$D_{i}\left(p_{i}\right) \geq 0, P R_{i} \geq 0 \forall i=1 \ldots N$

$W, P R_{i}$ are integers $\forall i=1 \ldots N$

Supplier's Problem:

$\operatorname{Max}_{S}\left(P R_{1}, P R_{2}, \ldots \ldots P R_{N}\right)$

$=$ Revenue - Total cost of regular production - Total inventory carrying cost

-Total cost of extended capacity + Total premium paymentrecieved

-Total Penalty paid

$\operatorname{Max} \pi_{S}\left(P R_{1}, P R_{2}, \ldots \ldots P R_{N}\right)$ 


$$
\begin{aligned}
& =\left(C_{1}-C_{2}-\frac{1}{2} h_{S}\right) \sum_{i=1}^{N} D_{i}\left(p_{i}\right)-\left(C_{3}-C_{2}\right) W+\alpha C_{1} \sum_{i=1}^{N} P R_{i} \\
& -\beta C_{1}\left(\sum_{i=1}^{N}\left(P R_{i}\right)-W\right)
\end{aligned}
$$

Both problems are optimized over the same set of decision variables. Hence,

Joint optimization problem:

$$
\begin{aligned}
& \operatorname{Max} \pi\left(P R_{1}, P R_{2}, \ldots \ldots P R_{N}\right)=\sum_{i=1}^{N} \pi_{r i}\left(\mathrm{PR}_{\mathrm{i}}\right)+\pi_{S}\left(P R_{1}, P R_{2}, \ldots \ldots P R_{N}\right)= \\
& \sum_{i=1}^{N}\left(D_{i}\left(p_{i}\right)\left(p_{i}-C_{2}-\frac{1}{2}\left(h_{S}+h_{r i}\right)\right)\right)-\left(C_{3}-C_{2}\right) \sum_{i=1}^{N} P R_{i}
\end{aligned}
$$

On substituting $D_{i}\left(p_{i}\right)=a_{i}-b_{i} p_{i}$

$$
\operatorname{Max} \pi\left(P R_{1}, P R_{2}, \ldots \ldots P R_{N}\right)=\sum_{i=1}^{N}\left(\left(a_{i}-b_{i} p_{i}\right)\left(p_{i}-C_{2}-\frac{1}{2}\left(h_{S}+h_{r i}\right)\right)\right)-\left(C_{3}-C_{2}\right) \sum_{i=1}^{N} P R_{i}
$$

Subject to

$$
p_{i} \geq C_{1}+\frac{1}{2} h_{r i}+\alpha C_{1} \frac{P R_{i}}{a_{i}-b_{i} p_{i}} \quad \forall i=1 \ldots N
$$

$$
\sum_{i=1}^{N}\left(a_{i}-b_{i} p_{i}\right) \leq K+W
$$

$$
W=\sum_{i=1}^{N} P R_{i}
$$

$a_{i}-b_{i} p_{i} \geq 0, P R_{i} \geq 0 \forall i=1 \ldots N$

$W, P R_{i}$ are integers $\forall i=1 \ldots N$ 
Table 2. Comparative results of all the four subcases

\begin{tabular}{|c|c|c|c|c|}
\hline Parameters & Subcase 1.1 & Subcase 1.2 & Subcase 2.1 & Subcase2.2 \\
\hline Joint Profit (in \$) & 39961.15 & 40627.3 & 38425.2 & 40224.07 \\
\hline 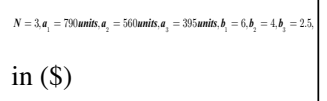 & 91.667 & 84.35 & 101 & 84.33 \\
\hline 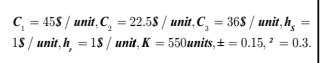 & 95.75 & 88.52 & 94.25 & 88.5 \\
\hline$p_{1}$ & 104.8 & 97.52 & 84.8 & 84.8 \\
\hline $\mathrm{PR}_{1}$ (in units) & - & 31 & - & 100 \\
\hline $\mathrm{PR}_{2}$ (in units) & - & 30 & - & 23 \\
\hline $\mathrm{PR}_{3}$ (in units) & - & 30 & - & 0 \\
\hline$p_{2}($ in $\$)$ (in units) & 240 & 284 & 184 & 284 \\
\hline$p_{3}($ in $\$)$ & 177 & 206 & 183 & 206 \\
\hline$D_{1}\left(p_{1}\right)$ & 133 & 151 & 183 & 183 \\
\hline W(in units) & - & 91 & - & 123 \\
\hline
\end{tabular}

The problem expressed by equation (33)-(37) is a bounded linear programming problem in $N$ variables, which will always possess an optimal solution and can be calculated through Lingo.

By solving and comparing the results of the aforementioned models, decisions regarding extended capacity $(W)$, and the number of premium units $\left(P R_{i}\right)$ of each retailer can be taken easily and optimally.

In the following section, it has been illustrated numerically that formulated models had reduced the bullwhip effect to a greater extent. The models are formulated in such a way that the impact of rationing is getting eliminated and the joint optimization of profit due to price-sensitive demand and rationing is mitigating the bullwhip effect.

\section{NUMERICAL ANALYSIS}

Both the cases and their subsequent subcases discussed above are illustrated in this section. All the four subcases have been solved with the same parameters and results are summarized in Table 1. Software Lingo has been used to solve the problems.

Example:

Consider a two echelon supply chain with a single supplier and 3 retailers. Symbols have their usual meanings.

$D_{2}\left(p_{2}\right)($ in units $)$ 


$$
D_{3}\left(p_{3}\right)(\text { in units })
$$

\section{Observations}

- It is evident from Table 2 that larger sales at lower price generate more profits as compared to lower sales at a higher price. Subcase 1.2 generates more profit than subcase 1.1 and subcase 2.2 generates more profit than subcase 2.1 .

- From Table 2, it is visible that profit is maximum for subcase 1.2, i.e. when the selling price of the retailer is an independent variable and supplier is extending his existing capacity, will generate maximum profit. In this subcase, since demand is evaluated from optimal price, the retailer would follow the truth inducing mechanism and bullwhip effect would get suppressed. Moreover, it favors the claim of Tai et al (2019) i.e. negative correlation between price and demand can be used as a tool to fight against bullwhip effect.

- In the case of price-sensitive demand and capacity constraint situation, suppliers should allocate according to the demand evaluated through optimal price rather than rationing. It can be verified by observing the corresponding subcase of both cases. Subcase 1.1 generates more profit as compared to subcase 2.1 and similarly subcase 1.2 generates more profit than subcase 2.2 . Furthermore, it should also be noticed that whether a premium payment scheme is there or not, treating the selling price of the retailer as an independent variable is more profitable for the supply chain as compared to the retailer's demand as an independent decision variable. It increases profit and reduces the bullwhip effect by avoiding rationing.

- In a capacity constraint scenario, the supply chain had to suffer with loss. Even in the case of price-sensitive demand, the selling price would not adjust the loss due to a reduction in supply. Capacity constraint condition usually generates manipulated demand, but as discussed in the model, Case 1 avoids rationing and case 2 allocates according to IPA, which supports truth inducing mechanism. Table 1 shows that three retailers have different maximum demands $\left(a_{i}\right)$, but they are getting approximately same allocation because of scarce supply. If they want more then they had to pay a premium for those units. If they inflate the demand they had to pay more premium and if they deflate, they will get lesser than their requirement. Hence, they had to reveal their true demand which mitigates the bullwhip effect. Hence presented model will defer the manipulation in demand and hence reduces the bullwhip effect.

- As depicted in Table1, profit in case of premium payment scheme (subcase $1.2 \&$ subcase 2.2) is always better as compared to respective non- premium payment subcase (subcase $1.1 \&$ subcase 2.1), It is independent of the selection of the independent decision variable, i.e. selling price or demand.

- Rationing and price variation (due to premium payment scheme and price-sensitive demand), forces the retailers to manipulate their demand and become a cause of bullwhip effect. Through the above discussion, it can be summarized that rationing and price variation nullifies the impact of distortion in demand i.e. bullwhip effect. Hence the model curbs bullwhip effect.

\section{SENSITIVITY ANALYSIS AND DISCUSSIONS}

In order to review the relative impact of the different parameters on the solution, sensitivity analysis has been performed on the above data set. Substantial changes are done in value of each given parameter $\left(C_{1}, C_{2}\right.$ and $\left.C_{3}\right)$ one at a time, and to note the effect on the optimum solution, results are tabulated and graphed. All the solutions have been evaluated using Lingo software. The impact of changes in the input parameters on the decision variables is summarized in Table 3. 
Table 3. Impact of changing $C_{1}, C_{2} \& C_{3}$ on supply chain profit \& extended capacity

\begin{tabular}{|c|c|c|c|c|c|c|c|}
\hline & & Subcase 1.1 & Subcase 1 & & Subcase 2.1 & Subcase & \\
\hline \multirow[t]{6}{*}{$C_{I}(\$ /$ unit $)$} & & $\boldsymbol{A}(\$)$ & W(Units) & $\boldsymbol{A}_{(\$)}$ & $\boldsymbol{A}(\$)$ & W(units) & $\boldsymbol{A}(\$)$ \\
\hline & 35 & 42711 & 141 & 44307.3 & 41175.2 & 163 & 44118.1 \\
\hline & 40 & 41336.2 & 116 & 42417.3 & 39800 & 143 & 42131.1 \\
\hline & 45 & 39961.2 & 91 & 40627.3 & 38425.2 & 123 & 40224.07 \\
\hline & 50 & 38586.2 & 66 & 38937.3 & 37050 & 103 & 38397.1 \\
\hline & 55 & 37211.2 & 41 & 37347.3 & 35675 & 83 & 36650.1 \\
\hline \multirow{5}{*}{$C_{2}(\$ /$ unit $)$} & 18 & 42436.15 & 119 & 43576.2 & 40900 & 145 & 43303.15 \\
\hline & 20.25 & 41198.7 & 105 & 42085.8 & 39662.7 & 134 & 41750.9 \\
\hline & 22.5 & 39961.15 & 91 & 40627.3 & 38425.2 & 123 & 400224.07 \\
\hline & 24.75 & 38723.7 & 76 & 39200 & 37187.7 & 111 & 38722.4 \\
\hline & 27 & 37486.2 & 63 & 37804.85 & 35950 & 100 & 37246.15 \\
\hline \multirow{5}{*}{$C_{3}(\$ /$ unit $)$} & 31.5 & \multirow{5}{*}{ Not Applicable } & 119 & 41101.1 & \multirow{5}{*}{$\begin{array}{l}\text { Not } \\
\text { Applicable }\end{array}$} & 145 & 40828.2 \\
\hline & 33.75 & & 105 & 40848.3 & & 134 & 40513.4 \\
\hline & 36 & & 91 & 40627.3 & & 123 & 400224.07 \\
\hline & 38.25 & & 76 & 40437.7 & & 111 & 39959.9 \\
\hline & 40.5 & & 63 & 40279.9 & & 100 & 39721.2 \\
\hline
\end{tabular}

\section{Observations}

- As the selling price of supplier increases $\left(C_{1}\right)$, supply chain profit $(\pi)$ and extended capacity $(W)$ (where ever applicable) both decrease. It is because the increase in supplier's selling price would cause an increase in retailer's selling price and hence in a reduction of demand because of price-sensitive demand. Through this observation, it can be claimed that in the case of pricesensitive demand, selling more quantity at a lower price would generate more profits as compared to selling a lesser quantity at a higher price.

- An increase in the production cost of the supplier $\left(C_{2}\right)$, would cause an increase in the selling price of the supplier $\left(C_{1}\right)$ and hence would cause a reduction in supply chain profit $(\pi)$ as well as extended capacity $(W)$.

- On increasing unit production cost of extended capacity $\left(C_{3}\right)$, the number of units produced on extended capacity would reduce, which is obvious. It will cause a reduction in sales and hence a reduction in supply chain profit. However, the rate of reduction, in this case, would be lower as compared to that of $C_{2}$, i.e. Increase in $C_{2}$ causes much reduction in $W$ as compared to increase in $C_{3}$. The reason could be explained as $C_{3}$ is impacting the price of only extended capacity which is very less as compared to routine capacity which is impacted by $C_{2}$.

To explain the comparative sensitivity of different subcases, for cost parameters $\left(C_{1}, C_{2}\right.$ and $\left.C_{3}\right)$ with respect to supply chain profits $(\pi)$ and extended capacity $(W)$, line charts are used. 


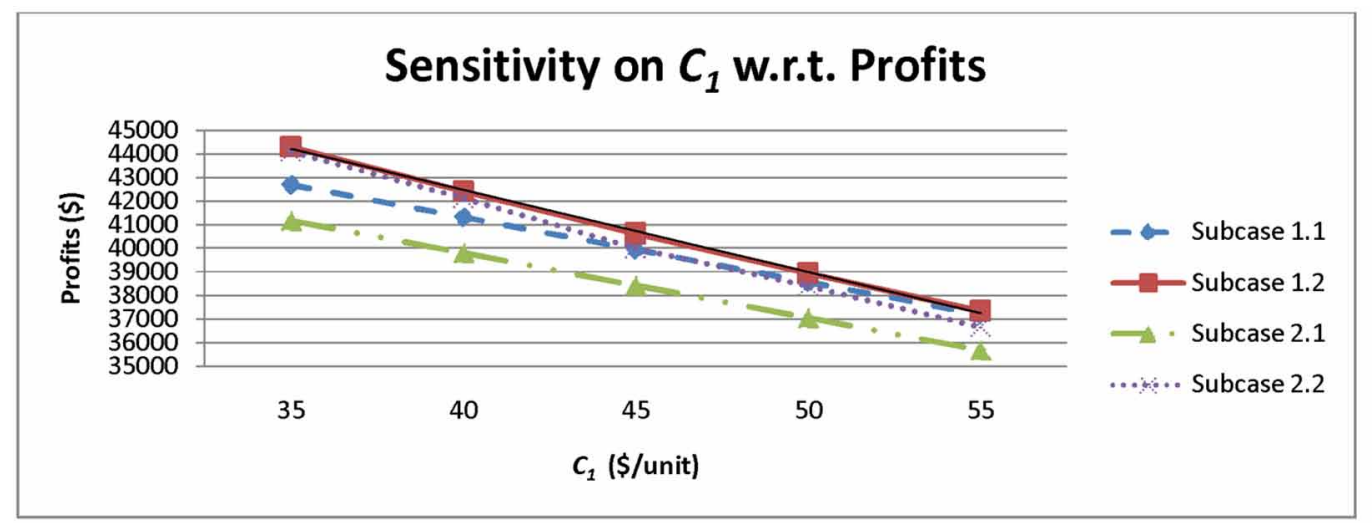

Figure 3 shows that the slope of subcase 1.1 and subcase 2.1 is minimum and approximately the same and for subcase 2.2 slope is maximum i.e., subcase 2.2 is most sensitive for change in $C_{1}$.

Figure 4. Sensitivity of $C_{1}$ (selling price of supplier) w.r.t. extended capacity on different subcases

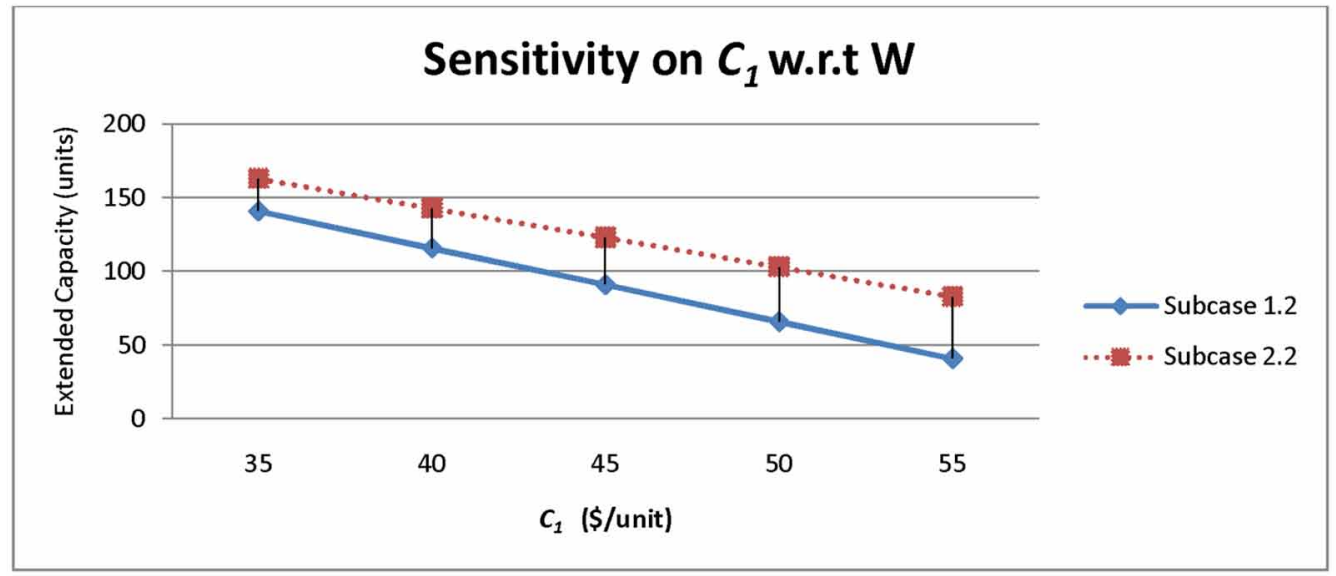

It can further be interpreted as the profit of the supply chain would be least affected on increasing supplier's selling price, when capacity could not be increased further i.e. subcase 1.1 and subcase 2.1. However, the bullwhip effect would be more in subcase 2.1 as compared to case 1.1 because of rationing. On increasing the supplier's selling price, the profit of subcase 2.2 would decrease most.

Figure 4 shows that the slope of subcase 1.2 is more than that of subcase 2.2 w.r.t extended capacity. Hence subcase 1.2 is more sensitive to $C_{1}$ as compared to subcase 2.2. Subsequently, on increasing supplier's selling price, there would be more reduction in extended capacity $(W)$, when the retailer's selling price is an independent variable as compared to demand as an independent variable.

From Figure 5, the slope of subcase 1.1 and subcase 2.1 is minimum and approximately the same and for subcase 2.2 slope is maximum i.e., subcase 2.2 is most sensitive for change in $\mathrm{C}_{2}$. 
Figure 5. Sensitivity of $C_{2}$ (cost price of supplier) w.r.t. profits on different subcases

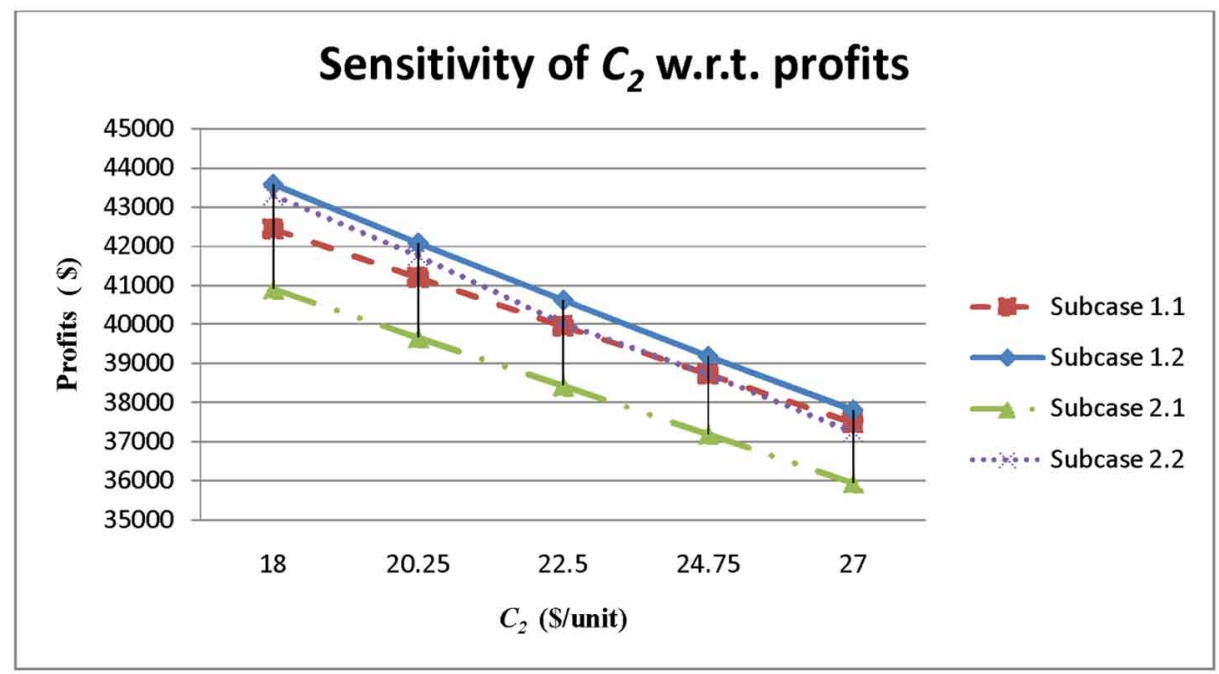

Figure 6. Sensitivity of $C_{2}$ (cost price of supplier) w.r.t. extended capacity on different subcases

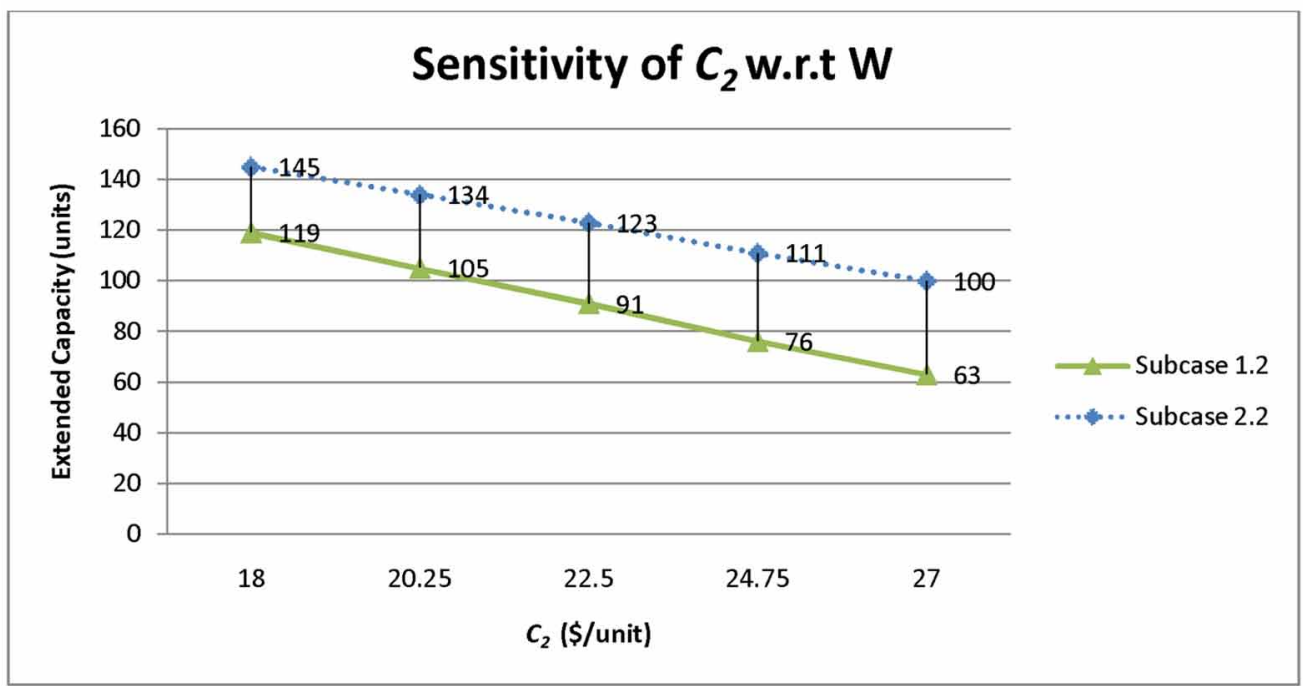




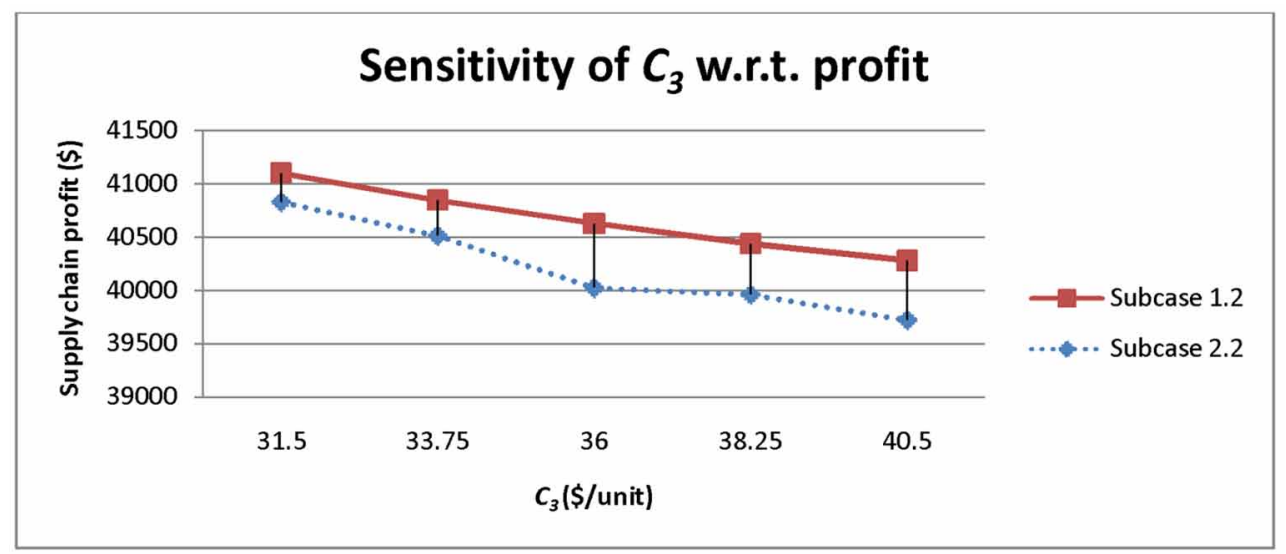

Figure 6 infers that the slope of subcase 1.2 is more than that of subcase 2.2 w.r.t extended capacity. Hence subcase 1.2 is more sensitive to $C_{2}$ as compared to subcase 2.2.

Figure 8. Sensitivity of $C_{3}$ (unit cost of extended capacity) w.r.t. extended capacity on different subcases

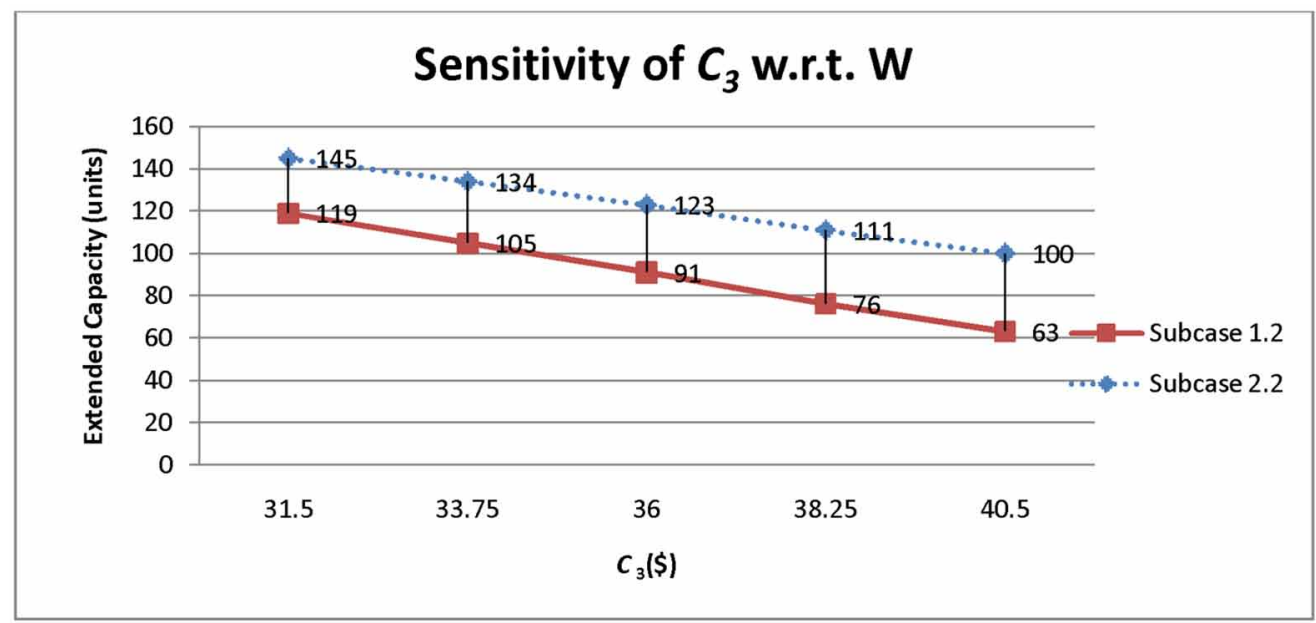

Figure 7 concludes that the slope of subcase 2.2 is more than that of subcase 1.2 ; hence subcase 2.2 is most sensitive for change in $C_{3}$.

Figure 8 infers that the slope of subcase 1.2 is more than that of subcase 2.2 w.r.t extended capacity. Hence subcase 1.2 is more sensitive to $C_{3}$ as compared to subcase 2.2.

\section{MANAGERIAL IMPLICATIONS}

Following managerial implications can be drawn from the paper: 
- It provides an optimal pricing and allocation policy, in presence of price-sensitive demand and capacity constraint monopolistic environment.

- It has been proved that the combined effect of negatively correlated price-sensitive demand and allocation policy helps in the reduction of the bullwhip effect.

- Introduction of a premium payment scheme helps in attaining better profits., in case of pricesensitive demand and monopolistic capacity constraint situation.

- The s

- $\quad$ elling price of the supplier $\left(C_{l}\right)$ is the most crucial and important cost component as its impact is maximum as compared to all other cost factors.

- The bullwhip effect is least when allocation is done corresponding to the optimal pricing of each retailer in presence of premium payment scenario.

\section{CONCLUSION AND FUTURE SCOPE}

Supply chain mechanisms that deal with price variation and shortage gaming needs special attention because both are considered as the main causes of the bullwhip effect. Through the present paper, a two echelon supply chain containing one supplier and $N$ retailers is investigated under a monopolistic environment. The capacitated supplier is receiving orders from retailers, who are experiencing price-sensitive demand. The retailers are offering premium payment to the supplier to motivate him to extend his existing capacity. Under stated situation, the proposed model analyzed the situation mathematically and four different mathematical programming problems are framed to cover all the scenarios of the situation. The idea of joint profit optimization is applied wherever the supplier and retailers are optimizing for same decision variables. The present model helps not only in mitigating the bullwhip effect but provides significant insight into the situation under consideration. It can be concluded that larger sales at lower price generate more profits as compared to lower sales at a higher price. When demand is taken as an independent variable instead of selling price of a retailer, it becomes more sensitive to change in cost parameters with respect to supply chain profit; however, sensitivity with respect to extended capacity would be more if the selling price of retailer would be taken as an independent variable. Moreover, in case of demand as an independent variable, the bullwhip effect would be high as compared to the case where the selling price of a retailer is an independent variable as retailers will get room to manipulate their demand. Offering a premium payment scheme is always beneficial for the supply chain. The suggested technique causes the traversal of true information across the supply chain and hence curbs bullwhip effect, as it is caused due to distorted information.

Further, the present paper has some scope of elaboration. During the development of models, only the linearly price-sensitive demand is used, however, in practical situations, the price-sensitive demand function can be quadratic, exponential or might have some other form. The present paper can be explored further with different types of price-sensitive demand functions. Instead of joint profit optimization, one can think about the optimization of individual profits. Furthermore, the situation can also be explored with multiple suppliers and probabilistic demand functions.

\section{ACKNOWLEDGMENT}

Authors would like to express their gratitude towards anonymous reviewers for their valuable suggestions and given us the opportunity to improve it to the present state. 


\section{REFERENCES}

Abad, P. L. (2001). Optimal price and order size for a reseller under partial backordering. Computers \& Operations Research, 28(1), 53-65. doi:10.1016/S0305-0548(99)00086-6

Abad, P. L., \& Jaggi, C. K. (2003). A joint approach for setting unit price and the length of the credit period for a seller when end demand is price sensitive. International Journal of Production Economics, 83(2), 115-122. doi:10.1016/S0925-5273(02)00142-1

Agrawal, S., Sengupta, R. N., \& Shanker, K. (2009). Impact of information sharing and lead time on bullwhip effect and on-hand inventory. European Journal of Operational Research, 192(2), 576-593. doi:10.1016/j. ejor.2007.09.015

Alfares, H. K., \& Ghaithan, A. M. (2016). Inventory and Pricing Model with Price-Dependent Demand, TimeVarying Holding Cost, and Quantity discounts. Computers \& Industrial Engineering, 94, 170-177. doi:10.1016/j. cie.2016.02.009

Cachon, G. P., \& Lariviere, M. A. (1999 a). Capacity choice and allocation: Strategic behavior and supply chain performance. Management Science, 45(8), 1091-1108. doi:10.1287/mnsc.45.8.1091

Cachon, G. P., \& Lariviere, M. A. (1999b). An equilibrium analysis of linear, proportional and uniform allocation of scarce capacity. IIE Transactions, 31(9), 835-849. doi:10.1080/07408179908969885

Chao, X., Gong, X., \& Zheng, S. (2016). Optimal pricing and inventory policies with reliable and random-yield suppliers: Characterization and comparison. Annals of Operations Research, 241(1-2), 35-51. doi:10.1007/ s10479-014-1547-0

Chatfield, D. C., Kim, J. G., Harrison, T. P., \& Hayya, J. C. (2004). The bullwhip effect - Impact of stochastic lead time, information quality, and information sharing: A simulation study. Production and Operations Management, 13(4), 340-353. doi:10.1111/j.1937-5956.2004.tb00222.x

Chen, H., Chen, Y. F., Chiu, C. H., Choi, T. M., \& Sethi, S. (2010). Coordination mechanism for the supply chain with leadtime consideration and price-dependent demand. European Journal of Operational Research, 203(1), 70-80. doi:10.1016/j.ejor.2009.07.002

Chen, L., Chen, X., Keblis, M. F., \& Li, G. (2019). Optimal pricing and replenishment policy for deteriorating inventory under stock-level-dependent, time-varying and price-dependent demand. Computers \& Industrial Engineering, 135, 1294-1299. doi:10.1016/j.cie.2018.06.005

Chopra, S \& Meindl, P. (2006). Supply Chain management: Strategy, planning and operation. Pearson Prentice Hall.

De Felice, F., \& Petrillo, A. (2013). A Strategic Multicriteria Decision Support System to Assess the Best Supply Chain Distribution Strategy and Characterize the Bullwhip Effect. International Journal of Information Systems and Supply Chain Management, 6(4), 61-76. doi:10.4018/ijisscm.2013100104

Forrester, J. W. (1961). Industrial dynamics. The Journal of the Operational Research Society, 48(10), 1037-1041. doi:10.1057/palgrave.jors.2600946

Geary, S., Disney, S. M., \& Towill, D. R. (2006). On bullwhip in supply chains-Historical review, present practice and expected future impact. International Journal of Production Economics, 101(1), 2-18. doi:10.1016/j. ijpe.2005.05.009

Geng, Q., \& Mallik, S. (2007). Inventory competition and allocation in a multi-channel distribution system. European Journal of Operational Research, 182(2), 704-729. doi:10.1016/j.ejor.2006.08.041

Hamister, J. W., \& Suresh, N. C. (2008). The impact of pricing policy on sales variability in a supermarket retail context. International Journal of Production Economics, 111(2), 441-455. doi:10.1016/j.jpe.2007.01.011

Hohmann, S., \& Zelewski, S. (2011). Effects of vendor-managed inventory on the bullwhip effect. Management Innovations for Intelligent Supply Chains, IGI Global, 4(3), 167-183. doi:10.4018/jisscm.2011070101

Jaggi, C. K., Aggarwal, K. K., \& Verma, M. (2010). Allocation game in a single period supply chain model. Revista Investigación Operacional, 31(3), 258-267. 
Jaggi, C. K., Verma, M., \& Jain, R. (2018). Quantitative Analysis for Measuring and Suppressing Bullwhip Effect. Yugoslav Journal of Operations Research, 28(3), 415-433. doi:10.2298/YJOR161211019J

Kaplan, A. (1969). Stock rationing. Management Science, 15(5), 260-267. doi:10.1287/mnsc.15.5.260

Kelle, P., Kelle, P., \& Milne, A. (1999). The effect of (s, S) ordering policy on the supply chain. International Journal of Production Economics, 59(1-3), 113-122. doi:10.1016/S0925-5273(98)00232-1

Kim, J., Hong, Y., \& Kim, T. (2011). Pricing and ordering policies for price-dependent demand in a supply chain of a single retailer and a single manufacturer. International Journal of Systems Science, 42(1), 81-89. doi:10.1080/00207720903470122

Kumar, B. K., Nagaraju, D., \& Narayanan, S. (2014). Optimality of inventory decisions and shipment policies in a two-echelon inventory system under quadratic price dependent demand. Procedia Engineering, 97, 2279-2288. doi:10.1016/j.proeng.2014.12.472

Lee, H. L., Padmanabhan, V., \& Whang, S. (1997a). The bullwhip effect in supply chains. Sloan Management Review, 38, 93-102.

Lee, H. L., Padmanabhan, V., \& Whang, S. (1997b). Information distortion in a supply chain: The bullwhip effect. Management Science, 43(4), 546-558. doi:10.1287/mnsc.43.4.546

Liu, G., Yang, T., Wei, Y., \& Zhang, X. (2019). Coordination and decision of supply chain under: Pricedependent demand and customer balking behavior. International Journal of Information Systems and Supply Chain Management, 12(3), 21-46. doi:10.4018/JJISSCM.2019070102

Mallik, S., \& Harker, P. T. (2004). Coordinating supply chains with competition: Capacity allocation in semiconductor manufacturing. European Journal of Operational Research, 159(2), 330-347. doi:10.1016/j. ejor.2003.08.019

Mo, J., Mi, F., Zhou, F., \& Pan, H. (2009). A note on an EOQ model with stock and price sensitive demand. Mathematical and Computer Modelling, 49(9-10), 2029-2036. doi:10.1016/j.mcm.2008.10.012

Nahmias, S., \& Demmy, W. S. (1981). Operating characteristics of an inventory system with rationing. Management Science, 27(11), 1236-1245. doi:10.1287/mnsc.27.11.1236

Osborne, M. J. (2007). Mathematical methods for economic theory: a tutorial. University of Toronto.

Özelkan, E. C., \& Çakanyıldırım, M. (2009). Reverse bullwhip effect in pricing. European Journal of Operational Research, 192(1), 302-312. doi:10.1016/j.ejor.2007.09.009

Polatoglu, H., \& Sahin, I. (2000). Optimal procurement policies under price-dependent demand. International Journal of Production Economics, 65(2), 141-171. doi:10.1016/S0925-5273(98)00240-0

Ray, S., Gerchak, Y., \& Jewkes, E. M. (2005). Joint pricing and inventory policies for make-to-stock products with deterministic price-sensitive demand. International Journal of Production Economics, 97(2), 143-158. doi:10.1016/j.ijpe.2004.06.054

Sodhi, M. S., Sodhi, N. S., \& Tang, C. S. (2014). An EOQ model for MRO customers under stochastic price to quantify bullwhip effect for the manufacturer. International Journal of Production Economics, 155, 132-142. doi:10.1016/j.ijpe.2013.12.020

Tai, P. D., Duc, T. T. H., \& Buddhakulsomsiri, J. (2019). Measure of bullwhip effect in supply chain with price-sensitive and correlated demand. Computers \& Industrial Engineering, 127, 408-419. doi:10.1016/j. cie.2018.10.027

Trapero, J. R., \& Pedregal, D. J. (2016). A novel time-varying bullwhip effect metric: An application to promotional sales. International Journal of Production Economics, 182, 465-471. doi:10.1016/j.jpe.2016.10.004

Wang, X., \& Disney, S. M. (2016). The bullwhip effect: Progress, trends and directions. European Journal of Operational Research, 250(3), 691-701. doi:10.1016/j.ejor.2015.07.022

Wu, D., Teng, J., Ivanov, S., \& Anyu, J. (2021). Empirical Assessment of Bullwhip Effect in Supply Networks. International Journal of Information Systems and Supply Chain Management, 14(2), 69-87. doi:10.4018/ IJISSCM.2021040104 
Yang, J., \& Yang, S. (2007). The use of a premium-payment scheme in a supply chain involving capacity acquisition. European Journal of Operational Research, 181(1), 207-223. doi:10.1016/j.ejor.2006.05.039

You, P. S., \& Hsieh, Y. C. (2007). An EOQ model with stock and price sensitive demand. Mathematical and Computer Modelling, 45(7-8), 933-942. doi:10.1016/j.mcm.2006.09.003

Mona Verma is working as an assistant professor in Shaheed Sukhdev College of Business Studies, University of Delhi. She has earned her Ph.D. in Inventory Management from the Department of Operational Research, Faculty of Mathematical Sciences, University of Delhi. Her research interest lies in the field of Inventory Management and Supply Chain Management. She has publications in many international journals like Revista Investigacion Operacional (Cuba), YUJOR, International Journal of Applied Operations Management, International Journal of Logistics and Supply Chain Management, International Journal of Industrial and System Engineering, OPSEARCH, IJORO, Applied Mathematics and Computation. She has attended many national as well as international conferences.

Reena Jain is a research scholar in Department of Operational Research, University of Delhi. She has earned dual masters, one in Operational Research from the Department of Operational Research, Faculty of Mathematical Sciences, University Of Delhi and the other in Mathematics from Department of Mathematics, C.C.S. University. She has qualified NET. Her research interest lies in the field of Inventory Management and Supply Chain Management. She has published papers in proceedings of ICPQROM and International Journal of Strategic Decision Sciences, YUJOR and AIMS etc. She has published one chapter also in a book "Analytical Approaches to Strategic Decision Making Interdisciplinary Consideration" published by IGI global.

Chandra K. Jaggi, Professor, Department of Operational Research, University of Delhi, Delhi, India. Recipient of different awards - Amity Academic Excellence Award 2019, Life Time Achievement Award 2018, International Best Researcher Award 2017, Certificate of Excellence "BHARAT VIKAS AWARD - 2017, Best Teacher Award" in 2017, IEOM Outstanding Service Award, USA, 2016, Certificate of Excellence 2014, Certificate for his Exceptional Contributions in the field of Inventory Management 2010, Certificate for his Significant Contributions in Operation Management 2009, Shiksha Rattan Puraskar 2007. He is Fellow Member of Operational Research Society of India \& International Science Community Association. He is Editor-in-Chief of IJICM and Associate Editor of IJSAEM \& OPSEARCH Springer, and Editorial Board of the IJSS: Operations \& Logistics, IJSOI, AJOR, IJECBS, JASR, and AJBAS. His research interest lies in the field of Supply Chain and Inventory Management. He has published more than 151 papers in International and National Journals. 